\title{
COMPUTATIONAL TAHANAN KAPAL UNTUK MENENTUKAN DAYA MESIN UTAMA KAPAL IKAN 5 GT
}

\author{
Sarwoko $^{1}$, Budhi Santoso ${ }^{2}$ \\ ${ }^{1)}$ Program Studi D-III Teknik Perkapalan, Sekolah Vokasi, Universitas Diponegoro \\ ${ }^{2)}$ Jurusan Teknik Perkapalan, Politeknik Negeri Bengkalis \\ Email : $\underline{\text { sarwoko@undip.ac.id }}$
}

\begin{abstract}
Abstrak
Variabel utama dalam menentukan daya mesin utama kapal adalah tahanan kapal yang dihasilkan oleh bentuk lambung kapal. perhitungan tahanan kapal dapat dilakukan dengan menggunakan perhitungan matematis. Penelitian ini bertujuan menentukan tahanan total kapal dan memperkiraan kebutuhan daya mesin kapal ikan 5 GT. Kapal 5 GT di redesain untuk mendapatkan sebuah model dengan menggunakan software naval Architecture. Model yang didapatkan berikutnya dilakukan perhitungan tahanan kapal dan kebutuhan daya kapal dilakukan. Metode perhitungan tahanan kapal menggunakan metode holtrop. Hasil analisa tahanan kapal dilihat dari beberapa variasi kecepatan untuk melihat bentuk aliran yang dihasilkan. Pada kecepatan dinas maksimal 15 knots menunjukan tahanan total kapal adalah $2.8 \mathrm{kN}$ dan kebutuhan dayanya adalah 35,7 Hp.
\end{abstract}

Kata Kunci : “tahanan kapal”, “kapal ikan”, “power mesin”.

\section{Pendahuluan}

Kapal bergerak dimedia air, adanya factor yang mempengaruhi pergerakan kapal di air salah satunya adalah hambatan. Hambatan kapal adalah merupakan factor yang sangat penting dalam proses mendesain suatu kapal karena factor ini berujung pada biaya. Semakin besar hambatan kapal, maka akan semakin besar penggunaan daya main engine yang dibutuhkan untuk menghasilkan dorongan kapal. Semakin besar daya main engine yang dipakai, berbanding linier dengan harga main engine tersebut. Dampak dari halt ersebut akan berpengaruh pada biaya operasional kapal yang tinggi karena membutuhkan konsumsi bahan bakar yang sangat banyak untuk menggerakkan main engine tersebut. Sehinga demikian, adalah tugas designer kapal untuk merancang kapal yang bentuk lambungnya akan menghasilkan hambatan yang rendah pada saat kapal tersebut bergerak diair.

Tantangan utama dalam mendapatkan efisiensi yang optimum, baik dari segi performa kapal maupun secara ekonomi. Salah satu target optimalisasi desain adalah bagaimana mendapatkan kecepatan kapal yang optimum dengan penggunaan daya mesin sekecil mungkin. Permasalahan yang sering terjadi adalah hambatan kapal yang masih terlalu besar yang merupakan factor penting terhadap efisiensi pada saat beroperasi dilaut. Kapal ikan tradisional yang digunakan di wilayah pesisir Indonesia dibangun dengan metode yang mengandalkan teknik tertentu dari ketrampilan yang diwarisi secara turun menurun oleh pengrajin kapal.

Tujuan penelitian adalah mencari karakteristik hambatan total kapal 5 GT di daerah pesisir Kepulauan Bengkali ssecara memanjang untuk mendapatkan nilai hambatan terendah sehingga akan mengurangi konsumsi energy pada saat kapal beroperasi.

\section{Tinjauan Pustaka}

\subsection{Tahanan Kapal Ikan}

Salah satu aspek yang mempengaruhi daya mesin kapal pada saat berlayar adalah tahanan kapal. terutama bentuk lambung kapal yang tercelub dalam air. Perhitungan tahanan dengan menggunakan bantuan computasi perbandingan dengan yang menggunakan rumus terdapat selisih $10,52 \%$ (Sugianto E, Dkk. 2017)

Variasi jarak sidehull dapat berpengaruh pada hasil tahanan gelombang terhadap tahanan total kapal (M. Adhan Fathoni, Dkk. 2012) 


\subsection{Maxsurf}

Maxsurf for academic adalah software freeware digunakan dalam mendesain sebuah model kapal. terdapat beberapa software disalam maxsurf antara lain : hydromax, hull speed, seakeeper, workshop dan span. Sofware maxsurf sendiri digunakan untuk membuat lines plan dalam bentuk 3D. Model kapal dapat dilihat potongan station, buttock, shear dan 3D-nya (Adin, 2010).

MAXSURF Resistance pada dasarnya adalah program prediksi resistensi. Sejumlah metode berbasis regresi dan satu metode analitis dapat digunakan untuk memprediksi resistensi bentuk lambung. Resistansi MAXSURF dapat menghitung komponen resistansi dalam bentuk koefisien. Namun, karena metode yang berbeda menggunakan formulasi yang berbeda, tidak semua komponen resistansi mungkin tersedia. Resistan total biasanya dipecah menjadi komponen tergantung nomor Froude resistansi gelombang (resistansi residuary) dan komponen dependen bilangan Reynolds resistansi kental (resistansi gesek). Nama yang diberi tanda kurung memberikan rincian alternatif:

Resistansi total $=$ Gelombang + Kental $=$ Residuari + Gesekan

Biasanya resistensi gesekan diprediksi menggunakan garis korelasi model-kapal ITTC atau formulasi serupa. Resistansi kental meliputi efek bentuk yang diterapkan pada resistansi gesekan sebagai berikut:

Resistensi viskos $=(1+\mathrm{k})$ Resistansi gesekan

dimana $(1+k)$ adalah faktor bentuk.

Bila memungkinkan, Resistansi MAXSURF menghitung semua komponen resistensi dan ini dapat diplot dan ditabulasi secara terpisah. Dalam beberapa kasus metode regresi memprediksi resistensi residu dan tidak ada faktor bentuk. Dalam kasus ini, tidak mungkin untuk menghitung hambatan gelombang (Maxsurf. 2017)

\section{Metode}

Penelitian dilakukan dengan menggunakan objek kapal ikan 3 GT yang berada di daerah pesisir pulau Bengkalis. Permodelan yang dilakukan pada software perkapalan adalah bentuk badan kapal yang tercelup dalam air. Software perkapalan yang digunakan adalah Software Maxsurf versi academic. Tahap pertama penyelesaian dimulai dari survey data utama kapal 3 GT. Survey ini bertujuan mendapatkan ukuran kapal yang akan dilakukan perhitungan daya mesin. Data ukuran utama kapal dapat dilihat pada table berikut ini:

Tabel 1. Ukuran utama Kapal Ikan 5 GT

\begin{tabular}{|l|l|}
\hline \multicolumn{2}{|c|}{ Ukuran utama Kapal } \\
\hline Panjang Seluruh LOA & 15 Meter \\
\hline Labar (B) & 2,8 Meter \\
\hline Tinggi (H) & 1,4 Meter \\
\hline Sarat Kapal (T) & 0,65 Meter \\
\hline
\end{tabular}

Tahap kedua berikutnya dilakukan redesain model kapal ikan 5 GT dengan menggunakan perangkat lunak. Tahap ketiga dilakukan running hambatan untuk mendapatkan kapal tersebut. Hambatan akan dirunning pada kecepatan kapal 8, 10, 12 knots untuk mendapatkan optimasi kecepatan yang ideal buat kapal 5 GT. Tahap terakhir penentuan daya mesin utama kapal ikan 5 GT.

\section{Hasil dan Pembahasan}

Data utama kapal digunakan sebagai acuan dalam membuat model kapal pada software. Seperti yang terlihat pada gambar 1 terlihat gambar model kapal ikan nelayan dengan ukuran 5 GT.

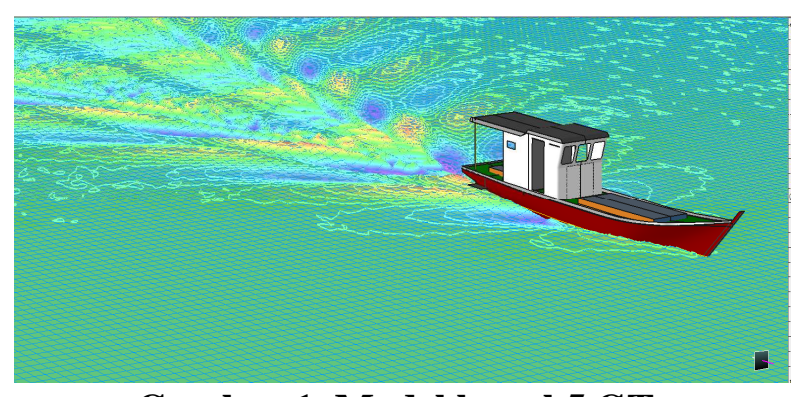

Gambar 1. Model kapal 5 GT 
Table 2.PerhitunganHambatanKapal

\begin{tabular}{lcl}
\hline \multicolumn{1}{c}{ MEASUREMENT } & VALUE & UNIT \\
\hline Displacement & 5.342 & $\mathrm{t}$ \\
\hline Volume (displaced) & 5211538.08 & $\mathrm{~cm}^{\wedge} 3$ \\
\hline Draft Amidships & $65 \quad \mathrm{~cm}$ \\
\hline Immersed depth & $64.18 \mathrm{~cm}$ \\
\hline WL Length & $1350.06 \mathrm{~cm}$ \\
\hline Beam max extents on WL & $243.1 \quad \mathrm{~cm}$ \\
\hline Wetted Area & $328062.17 \quad \mathrm{~cm}^{\wedge} 2$ \\
\hline Max sect. area & $10287.47 \quad \mathrm{~cm}^{\wedge} 2$ \\
\hline Waterpl. Area & $145574.68 \quad \mathrm{~cm}^{\wedge} 2$ \\
\hline Prismatic coeff. (Cp) & 0.375 & \\
\hline Block coeff. (Cb) & 0.247 & \\
\hline Max Sect. area coeff. (Cm) & 0.661 & \\
\hline Waterpl. area coeff. (Cwp) & 0.444 & \\
\hline KB & $42.86 \quad \mathrm{~cm}^{2}$ \\
\hline
\end{tabular}

Running hambatan kapal menggunakan method Holtrop dikarenakan lambung kapal ikan 5 GT berbentuk U. lambung kapal berbentuk $U$ memiliki nilai displacement besar. Kecepatan servis kapal ikan 5 GT di wilayah Kabupaten Bengkalis direncanakan antara 8 sampai dengan 15 knots. Table hasil running hambatan kapal menunjukkan pada kecepatan 8 knot nilai hambatan kapal $1.1 \mathrm{kN}$. Sedangkan power yang dibutuhkan untuk mengatasi hambatan tersebut adalah 7.3 Hp. Tabel menunjukkan pada kecepatan 12 knots hambatan kapal didapat $1.9 \mathrm{kN}$, sedangkan power yang dibutuhkan sebesar $19.5 \mathrm{Hp}$. Table hasil perhitungan hambatan kapal pada kecepatan 15 knots menunjukkan nilai hambatan kapal $2.8 \mathrm{kN}$, sedangkan power yang dibutuhkan sebesar $35.7 \mathrm{Hp}$. Berdasarkan hasil analisa tersebut menunjukkan ada perubahan power yang sangat ektris dari kecepatan 8 knots menuju 12 knots. Selengkapnya hasil perhitungan dengan menggunakan software maxsurft student version didapatkan perhitungan hambatan kapal sebagai berikut:
Table 3.PerhitunganHambatanKapal

\begin{tabular}{|c|c|c|c|}
\hline no & $\begin{array}{c}\text { speed } \\
\text { (kn) }\end{array}$ & $\begin{array}{c}\text { HOLTROP } \\
\text { RESISTANCE } \\
(\mathrm{Kn})\end{array}$ & $\begin{array}{c}\text { HOLTROP } \\
\text { POWER } \\
(\mathrm{hp})\end{array}$ \\
\hline 1 & O & -- & -- \\
\hline 2 & 0.5 & 0 & 0.002 \\
\hline 3 & 1 & 0 & 0.011 \\
\hline 4 & 1.5 & 0 & 0.037 \\
\hline 5 & 2 & 0 & 0.083 \\
\hline 6 & 2.5 & 0.1 & 0.157 \\
\hline 7 & 3 & 0.1 & 0.266 \\
\hline 8 & 3.5 & 0.1 & 0.415 \\
\hline 9 & 4 & 0.2 & 0.614 \\
\hline 10 & 4.5 & 0.2 & 0.877 \\
\hline 11 & 5 & 0.3 & 1.222 \\
\hline 12 & 5.5 & 0.4 & 1.669 \\
\hline 13 & 6 & 0.4 & 2.253 \\
\hline 14 & 6.5 & 0.5 & 3.035 \\
\hline 15 & 7 & 0.7 & 4.097 \\
\hline 16 & 7.5 & 0.9 & 5.503 \\
\hline 17 & 8 & 1.1 & 7.267 \\
\hline 18 & 8.5 & 1.3 & 9.353 \\
\hline 19 & 9 & 1.5 & 11.555 \\
\hline 20 & 9.5 & 1.5 & 12.658 \\
\hline 21 & 10 & 1.6 & 13.845 \\
\hline 22 & 10.5 & 1.7 & 15.121 \\
\hline 23 & 11 & 1.7 & 16.492 \\
\hline 24 & 11.5 & 1.8 & 17.962 \\
\hline 25 & 12 & 1.9 & 19.537 \\
\hline 26 & 12.5 & 2 & 21.478 \\
\hline 27 & 13 & 2.1 & 23.959 \\
\hline 28 & 13.5 & 2.3 & 26.617 \\
\hline 29 & 14 & 2.4 & 29.461 \\
\hline 30 & 14.5 & 2.6 & 32.496 \\
\hline 31 & 15 & 2.8 & 35.729 \\
\hline 32 & 15.5 & 2.9 & 39.165 \\
\hline 33 & 16 & 3.1 & 42.811 \\
\hline
\end{tabular}

Berikutnya membandingkan bentuk gelombang yang terjadi akibat adanya hambatan pada kapal. Pembagian berdasarkan kecepatan service kapal antara lain sebagai berikut ini.

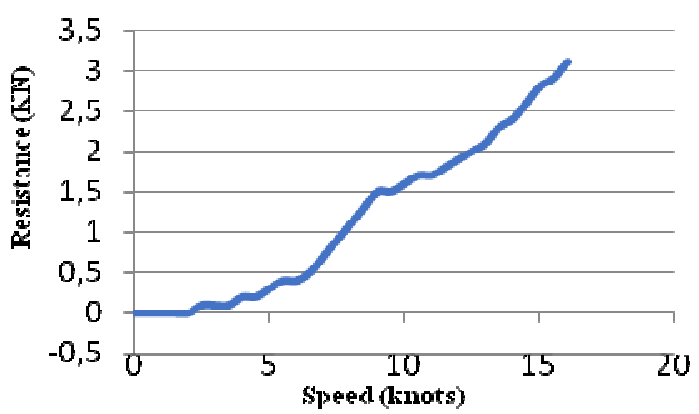

Gambar 2. Grafik Hambatan Kapal 5 GT

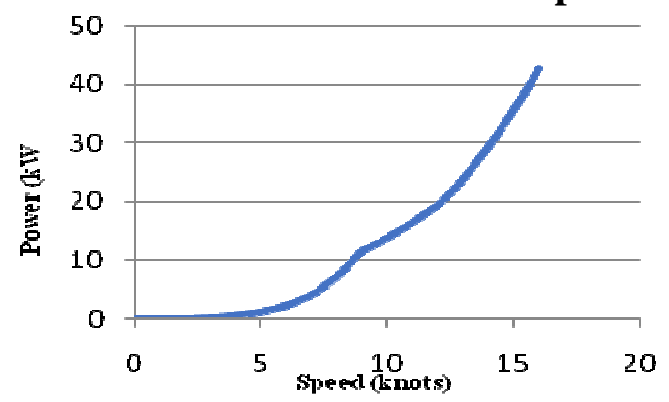

Gambar 3. Grafik Power Kapal 5 GT 


\subsection{Kapalpadakecepatan 8 knots}

Bentuk gelombang pada kecepatan 8 knots ditunjukkan oleh gambar berikut ini:

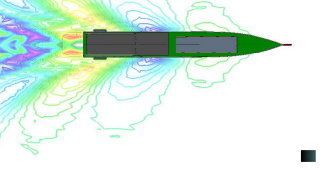

Gambar 4. Alur Gelombang kapal bergerak pada kecepatan 8 Knots

\subsection{Kapal pada kecepatan 12 knots}

Bentuk gelombang pada kecepatan 12 knots ditunjukkan oleh gambar berikut ini:

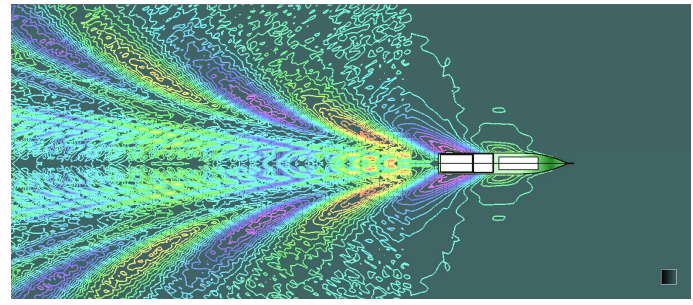

Gambar 5. Alur Gelombang kapal bergerak pada kecepatan 12 Knots

\subsection{Kapalpadakecepatan 15 konts}

Bentuk gelombang pada kecepatan 15 knots ditunjukkan oleh gambar berikut ini:

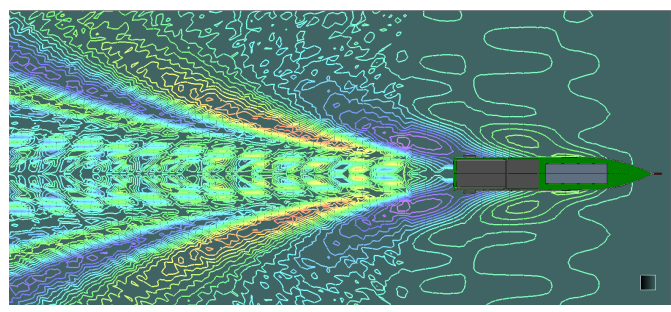

\section{Gambar 4. Alur Gelombang kapal bergerak pada kecepatan 15 Knots}

\section{Kesimpulan}

Dari analisis dan pembahasan maka untuk kecepatan 0 sampai 8 knots dihasilkan tahanan dan daya bernilai $1.1 \mathrm{kN}$. Kemudian setelah kecepatan terus bertambah maka nilai tahanan dan daya mengikuti naik dengan pola persamaan garis linier kuadrat. Pada kecepatan maksimal kapal ikan 5 GT 15 knots menghasilkan nilai tahanan total kapal adalah $2.8 \mathrm{kN}$ dan power yang dibutuhkan adalah $35.7 \mathrm{~kW}$.

\section{UcapanTerimakasih}

Kami dari hati yang paling dalam mengucapkan terima kasih kepada semua pihak yang telah terlibat dalam penelitian ini terutama mahasiswa, teknisi Jurusan Teknik Perkapalan. kepada Politeknik Negeri Bengkalis sebagai mitra dalam penelitian ini saya ucapkan banyak terima kasih. Serta secara khusus kami mengucapkan terima kasih kepada Program Studi D-III Teknik Perkapalan, Sekolah Vokasi, Universitas Diponegoro yang telah memberi dukungan atas penelitian ini.

\section{Daftar Pustaka}

- Adhan Fathoni, Dkk"Studi Eksperimental Tahanan dan Momen Melintang Kapal Trimaran Terhadap Variasi Posisi Dan Lebar Sidehull". JURNAL TEKNIK ITS Vol. 1, No. 1(Sept. 2012) ISSN: 2301-9271. Surabaya

- Adin sugiarto, 2010 https://cyberships.wordpress.com/na val-architecture/ship-design program/maxsurf/ Dilihat maret. 2019

- MAXSURF Resistance Program \& User Manual Bentley Systems, Incorporated. All rights reserved. Copyright (C) 2017

- Sugianto E, Dkk. Computational model tahanan kapal untuk menentukan kebutuhan daya kapal bulk carrier 8664DWT.http://journal.trunojoyo.a c.id/jurnal kelautan . Jurnal Kelautan Volume 10, No. 2, 2017 ISSN: 1907-9931 (print), 2476-9991 (online). Madura 